\title{
THE IN VITRO ACTIVITY OF CEFTEZOL (DEMETHYLCEFAZOLIN) AGAINST DENSE POPULATIONS OF ESCHERICHIA COLI
}

\author{
D. Greenwood and F. O'Grady \\ Department of Microbiology, University of Nottingham, \\ City Hospital, Nottingham NG5 1 PH, England \\ (Received for publication February 23, 1976)
}

\begin{abstract}
The activity of ceftezol was examined by continuous turbidimetric monitoring of dense populations of Escherichia coli exposed to the drug. Although ceftezol was found to be very active against strains of E. coli, its activity was consistently less than that of the closely related antibiotic, cefazolin. This difference was also found when strains of $E$. coli were examined in a dynamic system which simulates some of the conditions in which bacteria and drug interact in the treatment of bacterial cystitis.

Evidence is presented that the difference in activity between the two cephalosporins resides in a differential ability to induce certain morphological changes in $E$. coli and in a differential rate of destruction by escherichial $\beta$-lactamases.
\end{abstract}

The antibacterial activity of different $\beta$-lactam antibiotics often varies more than conventional in vitro tests indicate, most notably in their morphological effects on sensitive bacteria and their susceptibility to certain enterobacterial $\beta$-lactamases ${ }^{1,2}$. Cephalosporins in particular often exhibit similar antibacterial activity in conventional titrations, but differ substantially when dense bacterial populations are examined by continuous turbidimetric monitoring ${ }^{1,3,4)}$. In order to investigate these differences, we have developed methods of studying the reFig. 1. Structures of ceftezol and cefazolin.

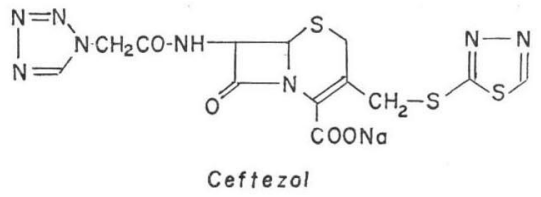
sponse of dense bacterial populations to $\beta$ lactam antibiotics by turbidimetry in static culture $^{1,5)}$ and in a mechanical model which simulates the hydrokinetic features of the urinary bladder ${ }^{6,7,8,8)}$.

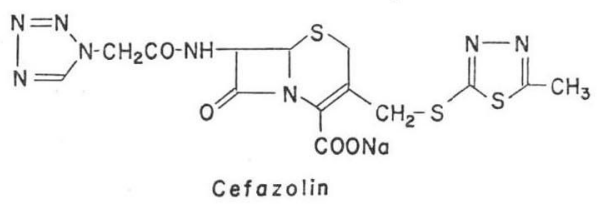

In the present study we have used these methods to assess the in vitro activity of a new cephalosporin, ceftezol (Fig. 1), a compound closely related structurally to cefazolin which has also recently been examined in this way ${ }^{10}$.'

\section{Materials and Methods}

Antibiotic: Sodium ceftezol was provided by Fujisawa Pharmaceutical Co., Ltd. Suitable concentrations were freshly prepared as required in sterile distilled water.

Growth medium: The 'complete' broth having an osmolality of about 325 milliosmoles per kilogramme, described elsewhere ${ }^{1)}$, was used.

Bacterial strains: Seven strains of Escherichia coli, all of which were originally isolated from infected urine, were examined. Two of the strains (ECSA 1 and ECSA 2) were sensitive to $4 \mu \mathrm{g}$ ampicillin per $\mathrm{ml}$, the remaining strains (Bur, Gen, Obr, Kin and Hos) were resistant 
to $500 \mu \mathrm{g}$ ampicillin per $\mathrm{ml}$ as judged by conventional titration in broth.

Static turbidimetric system: Cultures were grown from small inocula in broth in the multichannel bacterial growth monitoring device described by MACKINTOSH et al. ${ }^{11}$ in which the opacity of twelve independent bacterial cultures can be continuously recorded. Antibiotic was added at a standard point in the logarithmic growth phase equivalent to 30 per cent maximum opacity (viable count $\mathrm{ca} 5 \times 10^{7}$ organisms per $\mathrm{ml}$ ).

Bladder model: The design and operation of the in vitro bladder model have been described in detail elsewhere ${ }^{6,7,8,9)}$. In this system $20 \mathrm{ml}$ of an overnight broth culture of bacteria are diluted with fresh broth at $1 \mathrm{ml}$ per minute, simulating the rate of ureteric urine flow into the bladder. At preset intervals ( 1 hour in the present series of experiments) a 'micturition' episode empties the system of accumulated broth leaving a residual $20 \mathrm{ml}$ volume. Arrangements are made to mix the culture and the turbidity is continuously monitored photometrically. In the present study antibiotic was added as a single pulse, to achieve an initial concentration of $500 \mu \mathrm{g}$ per $\mathrm{ml}$, immediately after the fourth hourly 'micturition'.

Microscopy: Microscopical observations were made after 1 hour's exposure to antibiotic by interference contrast microscopy.

\section{Results}

\section{Morphological Response Profile}

The morphological changes induced in an ampicillin-sensitive strain of E. coli (ECSA 1) after one hour's exposure to ceftezol are compared with those induced by cefazolin in Fig. 2 . The ability of ceftezol to induce filamentation of $E$. coli was similar to that of cefazolin, but a higher concentration of ceftezol was required to induce spheroplast formation. Similar results were obtained using $E$. coli strain ECSA 2.

Turbidimetric Response Profile

The effect of adding various concentrations of ceftezol to an exponentially growing

Fig. 2. Morphological response profiles of an ampicillin-sensitive strain of E. coli (ECSA 1) after 1 hour's exposure to ceftezol or cefazolin.

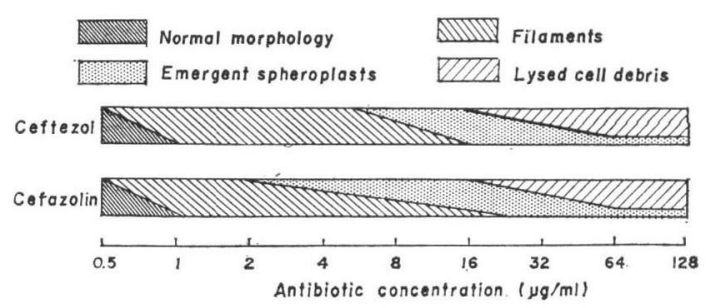
culture of $E$. coli ECSA 1 in the turbidimetric system is shown in Fig. 3. Concentrations of ceftezol exceeding $2 \mu \mathrm{g}$ per ml induced a decline in the opacity of the culture which occurred sooner as the concentration of antibiotic was increased. Regrowth of the culture occurred after a period which also varied with the anti-

Fig. 3. Continuous opacity records of an ampicillin-sensitive strain of E. coli showing the effect of various concentrations $(\mu \mathrm{g} / \mathrm{ml})$ of ceftezol (added at arrow) on exponentially growing cultures.

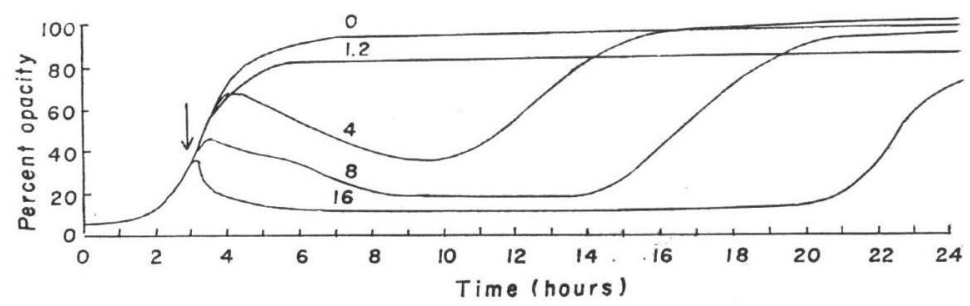


Fig. 4. Turbidimetric response profiles of an ampicillin-sensitive strain of E. coli (ECSA 1) showing the time elapsing after the addition of various concentrations of ceftezol or various other $\beta$-lactam antibiotics before A) lysis of the culture occurred; B) regrowth of the culture occurred.

$\mathrm{Ctz}=$ ceftezol $; \mathrm{Cez}=$ cefazolin $; \mathrm{Cer}=$ cephaloridine; $\mathrm{Amp}=$ ampicillin; $\mathrm{Ctn}=$ cephalothin; Cex $=$ cephalexin.

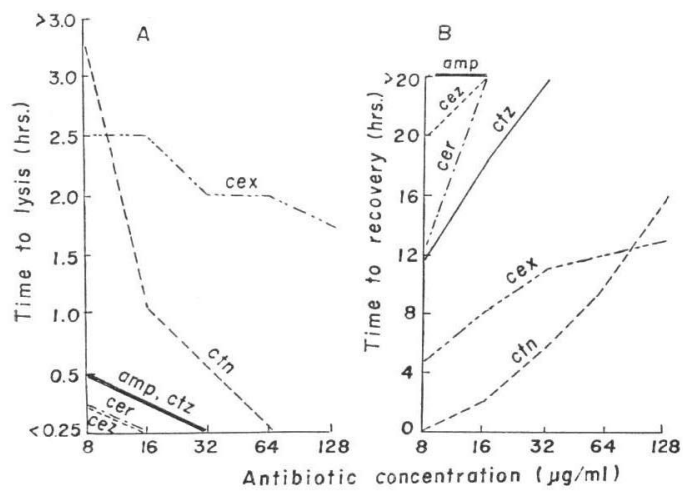

biotic concentration. $E$. coli strain ECSA 2 responded in a very similar fashion when examined in this way.

Data from records such as that shown in Fig. 3, obtained by continuous turbidimetric monitoring, was used to construct turbidimetric response profiles of various ampicillin-sensitive and -resistant $E$. coli strains for ceftezol and, using data reported elsewhere $\left.{ }^{1,5}, 10\right)$, other $\beta$ lactam antibiotics. Typical results are shown in Figs. 4, 5 and 6. These response profiles show the time taken following the addition of various concentrations of antibiotic, for A) lysis; B) regrowth of the culture to occur. The time to lysis reflects the intrinsic activity of the agent, the time to regrowth reflects its susceptibility to $\beta$-lactamases of the organism being tested ${ }^{1,5)}$.

In both resistance to $\beta$-lactamase and high intrinsic activity ceftezol closely resembled, but was slightly inferior to, the related cefazolin.

\section{Bladder Model}

E. coli ECSA 1 and four ampicillin-resistant E. coli strains (Bur, Obr, Kin, Hos) were examined in this system. Addition of sufficient ceftezol to achieve an initial concentration of $500 \mu \mathrm{g}$ per $\mathrm{ml}$ caused an immediate precipitous fall in opacity in all cases with recovery of the culture occurring after a period of time characteristic of the strain. The time taken for the opacity of the culture to reattain the level prevailing at the time of antibiotic addition is shown for each strain in Table 1, in which is included, for comparison, results previously obtained in this system using other $\beta$-lactam antibiotics, ${ }^{7,10)}$. According to the criterion of 
Table 1. Comparison of the times taken in the bladder model for cultures of $E$. coli to recover to the opacity level prevailing at the time of antibiotic addition after exposure to ceftezol and 5 other $\beta$-lactam agents

\begin{tabular}{l|c|c|c|c|c|c}
\hline \multirow{2}{*}{ Strain } & \multicolumn{5}{|c}{ Time (hours) to recovery after a single dose $(500 \mu \mathrm{g} / \mathrm{ml})$ of } \\
\cline { 2 - 3 } & Ceftezol & Cefazolin & Cephaloridine & Cephalothin & Cephalexin & Ampicillin \\
\hline ECSA 1 & 8 & 11 & 8 & 6.5 & 6 & 10 \\
Bur & 6 & 8 & 4.5 & 7.5 & 8 & NL \\
Kin & 4 & 7 & 6 & 7 & 5 & NL \\
Obr & 8 & 10 & 6 & 7 & 5 & NT \\
Hos & 4 & 3 & 2 & 4 & 3.5 & NT \\
\hline
\end{tabular}

$\mathrm{NL}=$ no lytic effect produced; $\mathrm{NT}=$ not tested

ability to suppress bacterial growth in this system ceftezol, in common with other cephalosporins tested, was less active than ampicillin against the ampicillin-sensitive strain ECSA 1. Tested against four ampicillin-resistant E. coli strains the activity of ceftezol was found generally to be between that of cephaloridine and that of cefazolin.

\section{Discussion}

Although ceftezol and cefazolin are closely related structurally, their in vitro activities against $E$. coli are not identical. The intrinsic activity of ceftezol against ampicillin-sensitive and -resistant strains of $E$. coli was found to be high, but generally lower than that of cefazolin. This appeared to be related to a diminished ability of the newer cephalosporin to induce spheroplast formation-a function thought to involve the inhibition of two enzymes ${ }^{12)}$.

When dense bacterial cultures are exposed to cephalosporins regrowth of ten occurs at antibiotic concentrations which initially cause lysis of much of the population. This regrowth is due to the general susceptibility of cephalosporins to enterobacterial $\beta$-lactamases and is seen even with ampicillin-sensitive $E$. coli strains which characteristically possess the ability to hydrolyse cephalosporins comparatively slowly ${ }^{11}$. The time taken for regrowth of the culture to occur under standard conditions of exposure to cephalosporins is chiefly an index of the susceptibility of the antibiotic to $\beta$-lactamase ${ }^{1,5)}$. When examined in this way ceftezol appeared to be somewhat more susceptible than cefazolin to escherichial $\beta$-lactamases, including the 'slow' $\beta$-lactamase of ampicillin-sensitive strains.

Ceftezol is structurally demethylcefazolin; these results again highlight the differences which a small modification of structure, apparently remote from the cephalosporin nucleus, can make to the properties of the whole molecule, a situation parallelled among penicillin congeners by differences in activity observed between ampicillin and hydroxyampicillin-amoxycillin ${ }^{13)}$. As in the case of ampicillin and amoxycillin, the difference in activity between ceftezol and cefazolin seems to be quite small and is manifested, at least in part, by a differential ability to cause various morphological changes in susceptible Gram-negative bacilli. It is possible that analysis of such differences, induced by minor modifications of the penicillin and cephalosporin molecules, may help in the elucidation of the problem of relating structure to function in this class of antimicrobial compounds.

\section{References}

1) Greenwood, D. \& F. O'Grady: Comparison of the responses of Escherichia coli and Proteus mirabilis to seven $\beta$-lactam antibiotics. J. Infect. Dis. 128: $211 \sim 222,1973$

2) Greenwood, D. \& F. O'Grady: FL 1060: a new beta-lactam antibiotic with novel properties. J. Clin. Path. 26: 1 6, 1973

3) Greenwood, D.; C. H. Chan-TeOH \& F. O'Grady: Assessment of susceptibility of ampicillin- 
resistant enterobacteria to cephalosporins. Antimicr. Agents \& Chemoth. 7: 693 697, 1975

4) Greenwood, D. \& F. O'Grady: Resistance categories of enterobacteria to $\beta$-lactam antibiotics. J. Infect. Dis. 132: 233 240, 1975

5) Greenwood, D.: Response profiles: a method of evaluating the activity of $\beta$-lactam antibiotics against enterobacteria. Chemotherapy, in press

6) O'Grady, F.; I. P. Mackintosh, D. Greenwood \& B. W. Watson: Treatment of 'bacterial cystitis' in fully automatic mechanical models simulating conditions of bacterial growth in the urinary bladder. Brit. J. Exp. Path. 54: 283 290, 1973

7) Greenwood, D. \& F. O'Grady: The comparative performance of beta-lactam antibiotics against ampicillin-sensitive Escherichia coli in conditions simulating those of the infected urinary bladder. Brit. J. Exp. Path. 55: 245 250, 1974

8) Greenwood, D. \& F. O'Grady: Response of ampicillin-resistant Escherichia coli to cephalosporins in an in vitro model simulating conditions of bacterial growth in the urinary bladder. Brit. J. Exp. Path. 56: 167 171, 1975

9) Greenwood, D.: Use of an in vitro model of the urinary bladder in the investigation of bacterial response to antibiotics. Proc. 9th Internat. Congr. Chemotherapy, in press

10) Greenwood, D.; C. H. Chan-Teoh \& F. O'Grady: Activity of cefazolin against dense populations of enterobacteria. Antimicr. Agents \& Chemoth. 7: 191 195, 1975

11) Mackintosh, I. P.; F. O’Grady, D. Greenwood, B. W. Watson, T. C. Crichton, R. Piper \& A. Ferrer: A twelve channel bacterial growth monitoring system. Biomed. Eng. 8: 514 515 \& 526,1973

12) Greenwood, D. \& F. O'Grady: The two sites of penicillin action in Escherichia coli. J. Infect. Dis. 128: 791 794, 1973

13) Rolinson, G. N.; A. C. MacDonald \& D. A. Wilson: Bactericidal action of amoxycillin on E. coli compared with other antibiotics. Proc. 9th Internat. Congr. Chemotherapy, in press 